\title{
A COMMON PATH
}

\section{ICELAND'S}

PRESIDENCY

2019

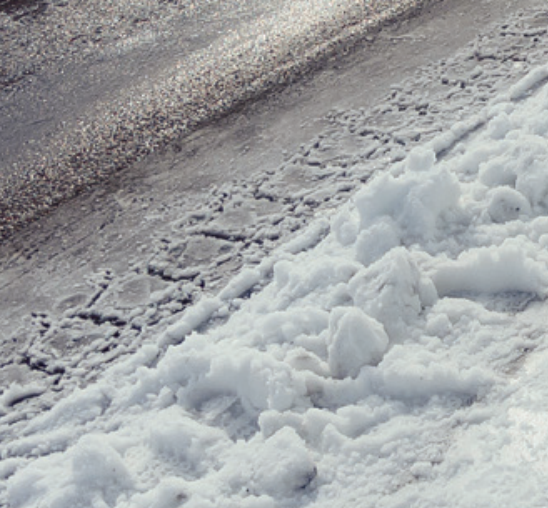

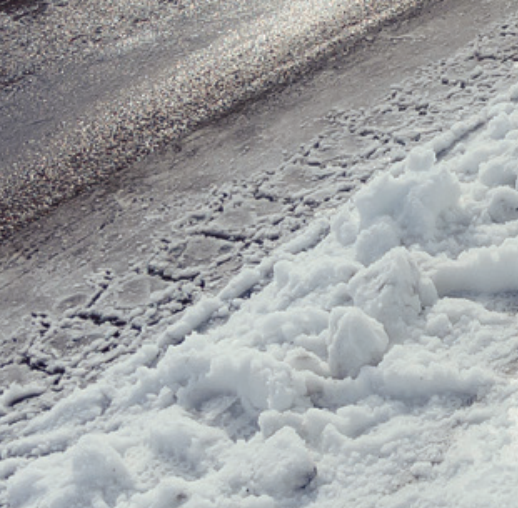

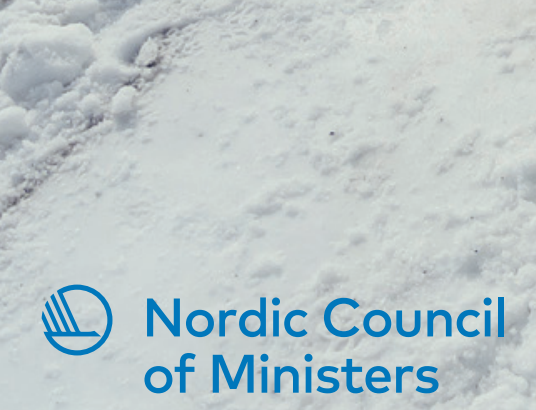

Q.

3

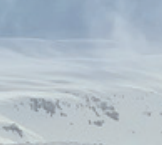




\section{A Common Path}

Iceland's Presidency of the Nordic Council of Ministers in 2019

ANP 2018:828

ISBN 978-92-893-5865-1 (PRINT)

ISBN 978-92-893-5866-8 (PDF)

ISBN 978-92-893-5867-5 (EPUB)

http://dx.doi.org/10.6027/ANP2018-828

(C) Nordic Council of Ministers 2018

Layout: Louise Jeppesen

Cover Photo: unsplash.com

Print: Rosendahls and 07 Media AS

Printed in Denmark and Norway

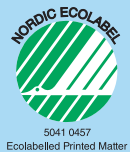

Icelands's Presidency of The Nordic Councils of Ministers in 2019 is a Green Presidency.

\section{Nordic co-operation}

Nordic co-operation is one of the world's most extensive forms of regional collaboration, involving Denmark, Finland, Iceland, Norway, Sweden, the Faroe Islands, Greenland, and Åland.

Nordic co-operation has firm traditions in politics, the economy, and culture. It plays an important role in European and international collaboration, and aims at creating a strong Nordic community in a strong Europe.

Nordic co-operation seeks to safeguard Nordic and regional interests and principles in the global community. Shared Nordic values help the region solidify its position as one of the world's most innovative and competitive.

\section{Nordic Council of Ministers}

Nordens Hus

Ved Stranden 18

DK-1061 Copenhagen

www.norden.org

Download and order Nordic publications from www.norden.org/nordpub 


\section{ICELAND'S PRESIDENCY OF THE NORDIC COUNCIL OF MINISTERS IN 2019}

\section{Contents}

4 Greetings from the Prime Minister and Minister for Nordic Co-operation

9 Youth in the Nordic Countries

13 Sustainable Tourism in the North

17 The Ocean - Blue Growth in the North

23 A Strong Nordic Voice

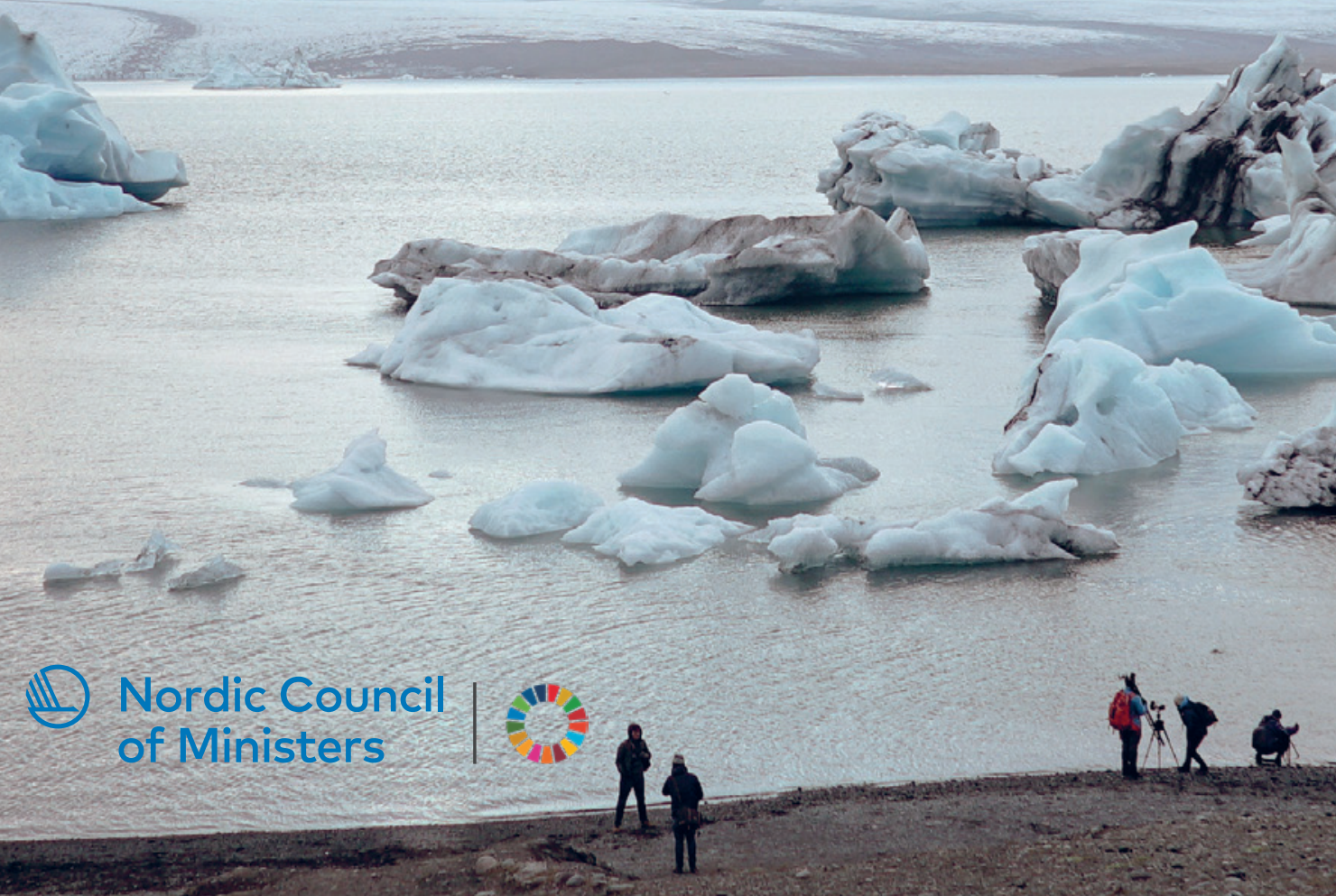




\section{Greetings from the Prime Minister and Minister for Nordic Co-operation}

to a true friend

the path is easy to tread though his home lies distant.

Hávamál, Sayings of the High One, from the codex Konungsbók Eddukvæða

en til góðs vinar

liggja gagnvegir,

bótt hann sé firr farinn

Hávamál, Konungsbók

Eddukvæða

Path, noun. A way or track laid down for walking or made by continual treading

Oxford English Dictionary

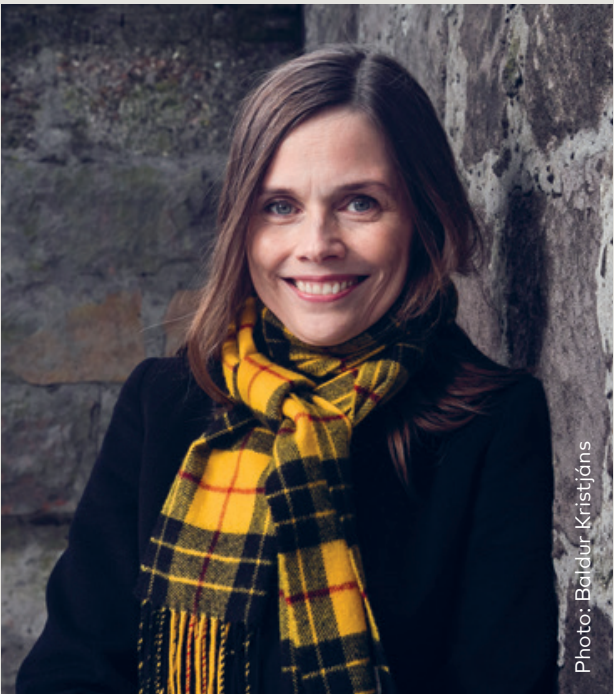

Prime Minister

Katrín Jakobsdóttir

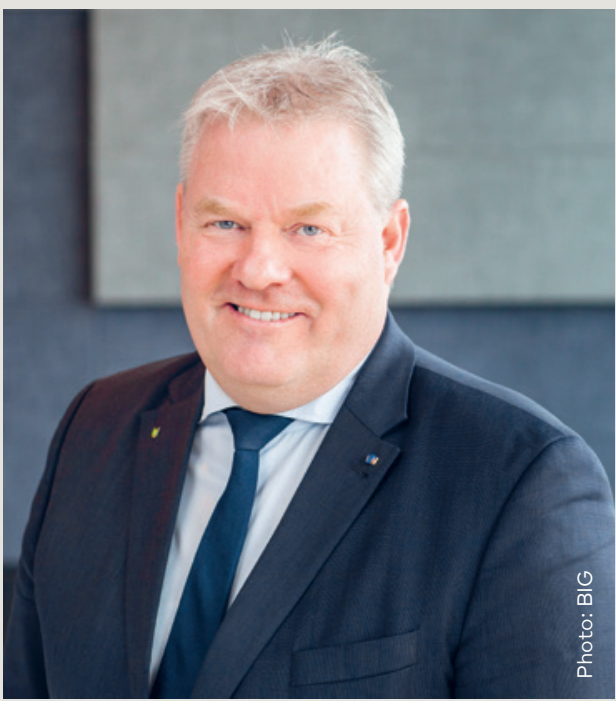

Minister for Nordic Co-operation

Sigurður Ingi Jóhannsson 
The theme of Iceland's Presidency of the Nordic Council of Ministers in 2019 is inspired by the Old Norse Hávamál, timeless wisdom codified by our Viking ancestors some 1000 years ago. This shared cultural heritage lays out a clear path for those wishing to lead a life of honour and maintain meaningful relationships. The author deplores, for instance, greed, falsehood and excess while praising integrity, diligence and, not least, friendship.

Hávamál teaches us that the path shared with a true friend - a common path - is always easy to tread.

And this is certainly true for the Nordic countries, from Reykjavik to Helsinki, Oslo to Nuuk, Tórshavn to Stockholm, Copenhagen to Mariehamn. Nordic citizens can move between countries without hindrances to study, work or set up a business. We are welcome guests in each other's countries and this mobility makes the Nordic countries the world's most integrated region, with strong economies and rich human capital.

Our connecting paths are not merely internal, they also link us to the outside world. Joint Nordic promotion in North America, Asia and elsewhere have shown that the Nordic countries can achieve more together than individually. "Nordic" is a fantastic brand, symbolising quality in products and services ranging from fish fillets to lamb chops, computer programs to architecture, internet television series to music on Spotify. The Nordic countries are open to the rest of the world, working together in Europe and fostering dialogue and co-operation with the broader world in finding solutions to global challenges.

Last but not least, our common path has helped shape the digital world. The highways of the future are digital and good Internet connections encapsulate the entire world in a single smart phone. The internet is a platform for business and innovation, promoting education and culture, welfare and well-being. The digital revolution offers countless opportunities, not least for small, remote communities. It's up to us to provide the digital routes and the Nordic countries intend to be at the forefront in introducing next generation $5 G$ systems.

The Icelandic Presidency will focus on issues concerning young people in the Nordic region - the generation born around the turn of the century beginning to make its way in life. We want to listen to young people and support projects that promote education, culture and health.

Secondly, we intend to launch projects in the field of sustainable tourism, where the Nordic countries face similar challenges. We need to find a balance between growth and sustainability, to welcome guests while ensuring the 


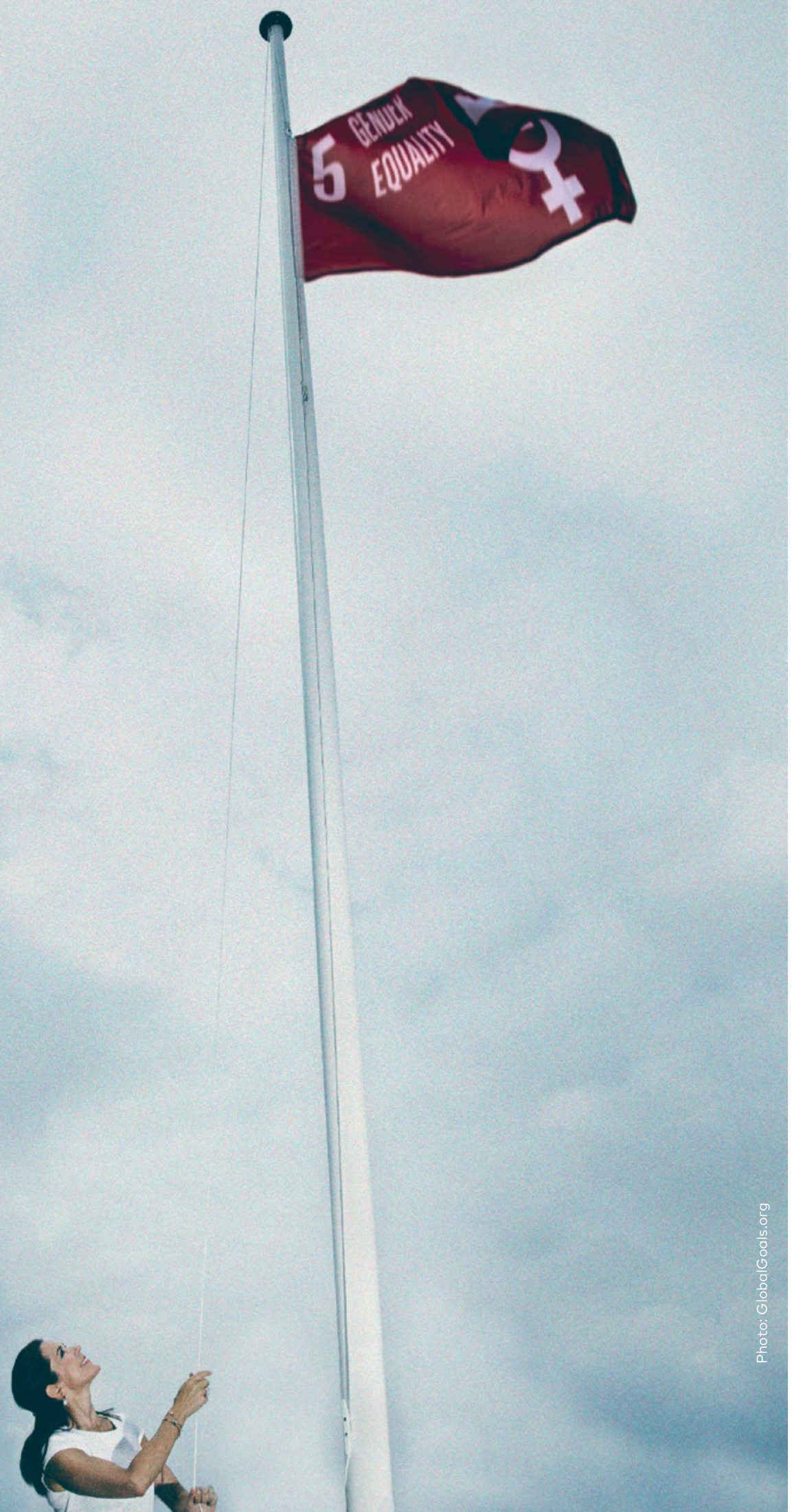


viability of our vulnerable natural environment.

Thirdly, our Presidency will place the oceans and the blue bioeconomy front and centre. The ocean connects the Nordic countries, creates jobs and value. The waters surrounding us face daunting environmental challenges and major collaborative efforts will be undertaken to clean and protect the seas, not least from plastic pollution.

The North Atlantic will be given special attention, as the area is an important part of the Nordic region, just as the Baltic Sea, the Barents Sea and the Arctic. Synergies will be sought with Iceland's presidency of the Arctic Council 2019-2021.

Our priorities and projects will fully incorporate gender equality, including actions linked to the \#metoo movement aimed at ending violence against women and stopping sexual harassment. The UN Global Goals will be specifically integrated into the Presidency Program. The Nordic countries play a leading role in implementing the Global Goals and have long focused on equal rights and equality, environment and climate, development co-operation and peaceful resolution of disputes.
There is a traditional saying about friendship: "Your friend is the one who points out your faults." These words also ring true today, not least in the face of division and partisanship, extremism and authoritarian trends which appear to be gaining strength throughout the world. They remind us that the Nordic countries must continue to be strong advocates of peace, human rights and humanitarianism based on international law and rules-based international institutions.

None of the above can be taken for granted. Even Nordic co-operation should not be taken for granted. It exists because of joint Nordic decisions that dialogue, respect and friendship provide the strongest basis for regional collaboration. That a strong welfare system is not contrary to but rather a premise for vital business and industry. That it is better to build bridges than walls, that diversity is a strength and not a weakness, and that we have to safeguard democracy and the rule of law, both at home and abroad.

\section{We look forward to continuing our strong Nordic co-operation in 2019 - see you in Iceland!}




\section{8}

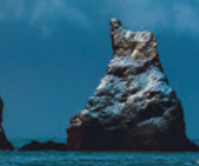




\section{YOUTH IN}

\section{THE NORDIC COUNTRIES}

During Iceland's Presidency in 2019 the generation born around the turn of this century will be finishing high school or vocational education, entering university or the labour market, leaving their parental homes and stepping out into society as young adults. The future is theirs. During the Presidency, the spotlight will be on youth, with projects in the areas of education, culture and health, emphasising active participation of and dialogue with youth representatives.

It is the policy of the Nordic Council of Ministers to make Nordic countries the best place in the world for children and young people. It is a worthwhile challenge and at the same time an opportunity to create more space for children and youth to grow and flourish as active individuals. Nordic cultural co-operation policy for 2013-2020 also places special emphasis on youth in Nordic countries, with the aim of enabling children and youth to create, enjoy and influence the arts and culture.

The UN Global Goals are a main factor in shaping Iceland's Presidency plans, as young people play a key role in achieving these goals. To make this possible young people need to be encouraged to actively participate in the society to be involved in taking important decisions. By doing so we give them a place in our community.
Educational institutions play a major role in implementing the Global Goals. Through education, young people acquire the skills and knowledge needed to increase their activity and participation in society and its development.

The Nordic countries have received groups of youths and children who need to build a new life in a new country. Making these new citizens feel at home and feel their contribution is important is a major challenge. Concerted efforts must be made to counteract the exclusion and isolation of this group.

The project Youth in the Nordic Countries consists of three components, like all the projects of the Icelandic Presidency. Children and youth are at the forefront in all the project components. Special emphasis is placed on equality, mobility and visibility.

The goal of the project Education for All is to have the Nordic countries lead the way in implementing the UN's fourth Global Goal, with particular emphasis on target 4.7. It covers all levels of education, which means first-class services and support for the countries' education systems and providing individuals with a variety of inclusive study and work options. In order to promote the democratic society, the basis needs to be laid for active participation at all levels of education, giving 

children and young people appropriate preparation and varied opportunities for further education or work. The three-part project involves a common Nordic mapping of the implementation of Global target 4.7, discussion amongst youth about the goal and educational materials with quality indicators for the future on its implementation.

Platform GÁTT is a forum that combines some of the Nordic countries' leading art festivals in projects aimed at providing the region's young artists with opportunities to connect with one another and to promote their creative work. Rapid developments in the international arena and the increase in the population originating from other cultures call for changes in Nordic co-operation, that pose challenge to adapt and at the same time offer opportunities for cultural innovation. It is important to support and develop cultural and artistic life in the Nordic countries by promoting innovation and increased links between artists and with Nordic art festivals and art events.
The Child's First 1000 Days covers the period from pregnancy until two years of age. During this important period, the child takes shape as an individual, with effects on its mental health later in life, such as during adolescence. The objective is to find the best ways to encourage good mental health and well-being in the early years of life, to give all children in the Nordic countries the best possible start in life. An analysis will be made of the current situation and gathering of best practices with regard to maternal mental health during pregnancy, encouraging emotional bonding between children and parents, early intervention for risk factors in the lives of babies and young children, and the well-being of the youngest children in preschools.
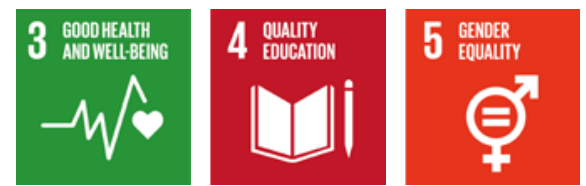


\section{SUSTAINABLE TOURISM IN THE NORTH}

Nature in the Nordic countries is characterised by biological and geological diversity - there is a considerable difference in both the nature and landscape from north to south and east to west. While large cities and more populated regions are typical of the southern and eastern areas, in the north and west the natural environment is sensitive, with large, unpopulated regions, sparse settlement and vast wilderness. Outdoor activities in communion with nature, together with traditional hospitality, are part of the fabric of the Nordic self-image and culture. Several well-known landmarks and natural wonders are found in the Nordic countries, which are popular with visitors for many reasons. The urbanisation of the past decades has only increased the need for and interest in enjoying this unique nature. At the same time the number of people who have the means of travelling about the world is growing, and even though many people want to visit the most popular destinations, the number who seek to enjoy nature far from the beaten track is steadily increasing.

In recent years, tourism has grown rapidly in the Nordic countries. The interplay of nature, culture and history, combined with investment in infrastructure and increased expertise, has created a favourable environment for the growth of travel services. The growing number of travellers raises various new challenges. Pressure on sensitive nature, necessary investment in improved infrastructure and security for travellers both on land and at sea are examples of major issues shared by the state and municipalities, as well as the travel service industry and the public.

It is important that Nordic countries learn from experience and share each other's solutions, with the aim of capturing the benefits offered by rapidly growing tourism, not least for expanding economic development in sparsely settled areas. It is the common objective of all Nordic countries to protect the natural and social qualities which are the basis for northern tourism and in so doing reinforce the status and competitiveness of the sector. Too many tourists in too small an area at the same time can both damage the natural environment and create a negative experience for the guests. This we want to avoid.

The priority implies Nordic co-operation on finding the balance between growth and protection in developing sustainable tourism. The intention is to gain an overview of the countries' common challenges and policies in this area. Increased emphasis on natural protection, sustainability, innovation and social responsibility in the travel indus- 
try will strengthen the sector in the long term, give local residents opportunities for active participation and encourage positive attitudes among them towards travel services. The main challenges and opportunities offered by the growing tourist industry in northern regions will be analysed. Emphasis is placed on the participation of all Nordic countries, with the aim of optimising the synergies available from the countries' co-operation.

The Presidency projects in the field of sustainable tourism in the North focus on tourism and nature conservation, emphasising primarily nature protection, climate issues, design and quality of infrastructure, not least with respect to the guests' experience; digitalisation of the travel industry for increased sustainability and competitiveness; and local food in the Nordic travel industry based on food traditions and culture, together with innovation in the spirit of New Nordic Food. Emphasis will be placed on introducing young people to the opportunities offered by sustainable tourism.

The aim is to involve young entrepreneurs in order to develop new solutions to selected issues concerning emphasis on sustainable tourism, in collaboration with the Nordic innovation environment and Nordic Innovation.

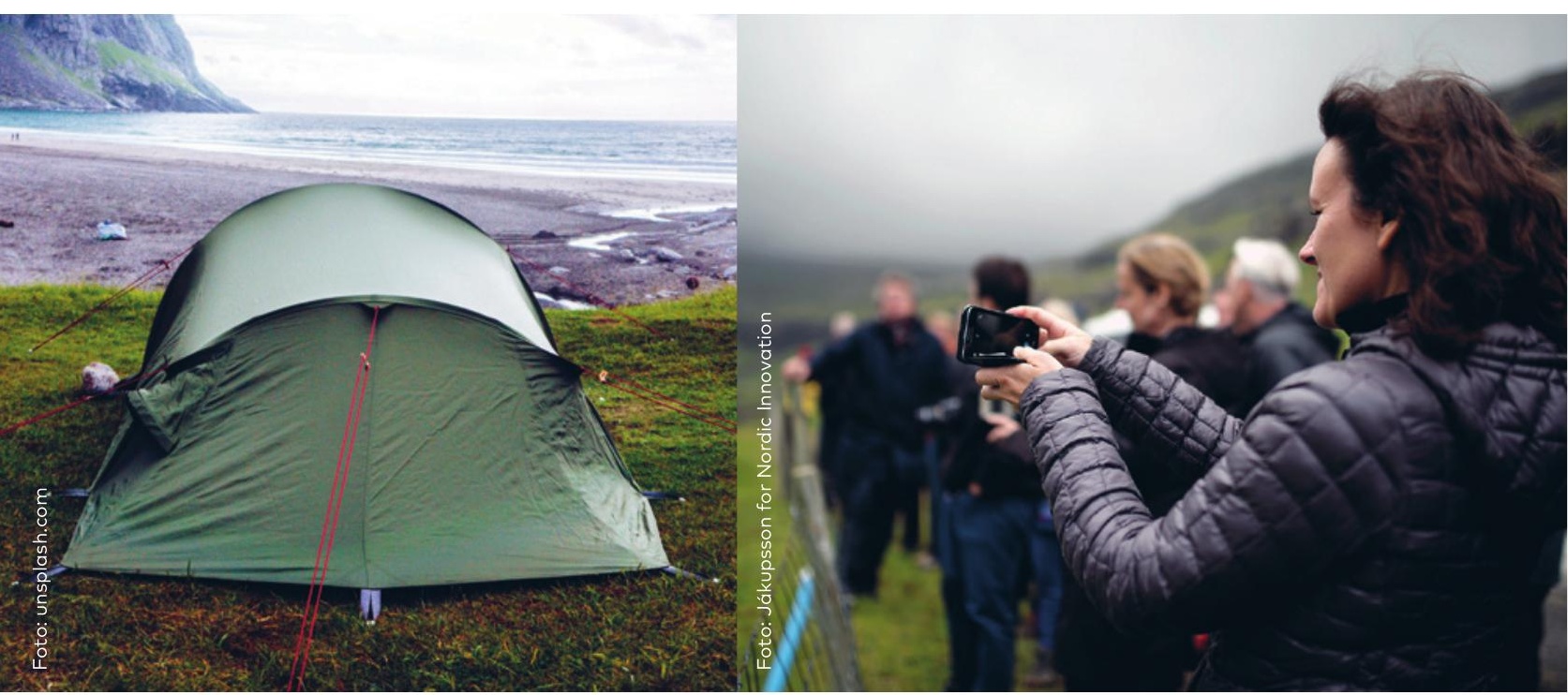


The project Tourism and Nature Conservation is aimed at increasing knowledge and sharing experience of the connection between tourism and national parks and other nature conservation areas in Nordic countries, especially in northern regions. Emphasis will be placed on formulating policy, arrangements for controlling visitor numbers, dissemination of information to travellers, infrastructure development including renewable energy transition in transportation, certification and operations, and other arrangements in national parks.

\section{Digitalisation of the Travel Industry is} aimed at increasing the ability of smaller travel service companies to take advantage of digital technology in their daily operations and marketing. A needs analysis will be carried out focusing on the expertise and capacity of small businesses to utilise digital technology, e.g. to manage the number of travellers in specific areas. Examples from Nordic countries of successful use of digital technology in tourism will be used to spread knowledge of best practices.

Local food in the Travel Industry is aimed at preparing travel services for the changes which can be expected in food production in the Nordic countries due to climate change, changes in travellers' consumption patterns and the expectations of visitors regarding local food. The project will examine how increased emphasis on the quality and diversity of local food, together with innovation in food production, can contribute to sustainable utilisation of food resources, new job opportunities and local value creation.
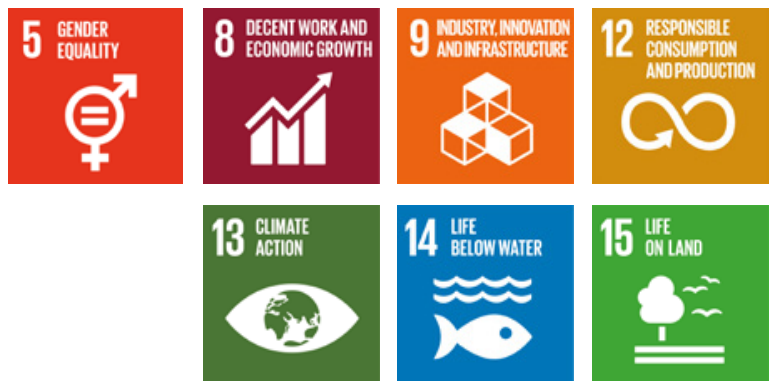


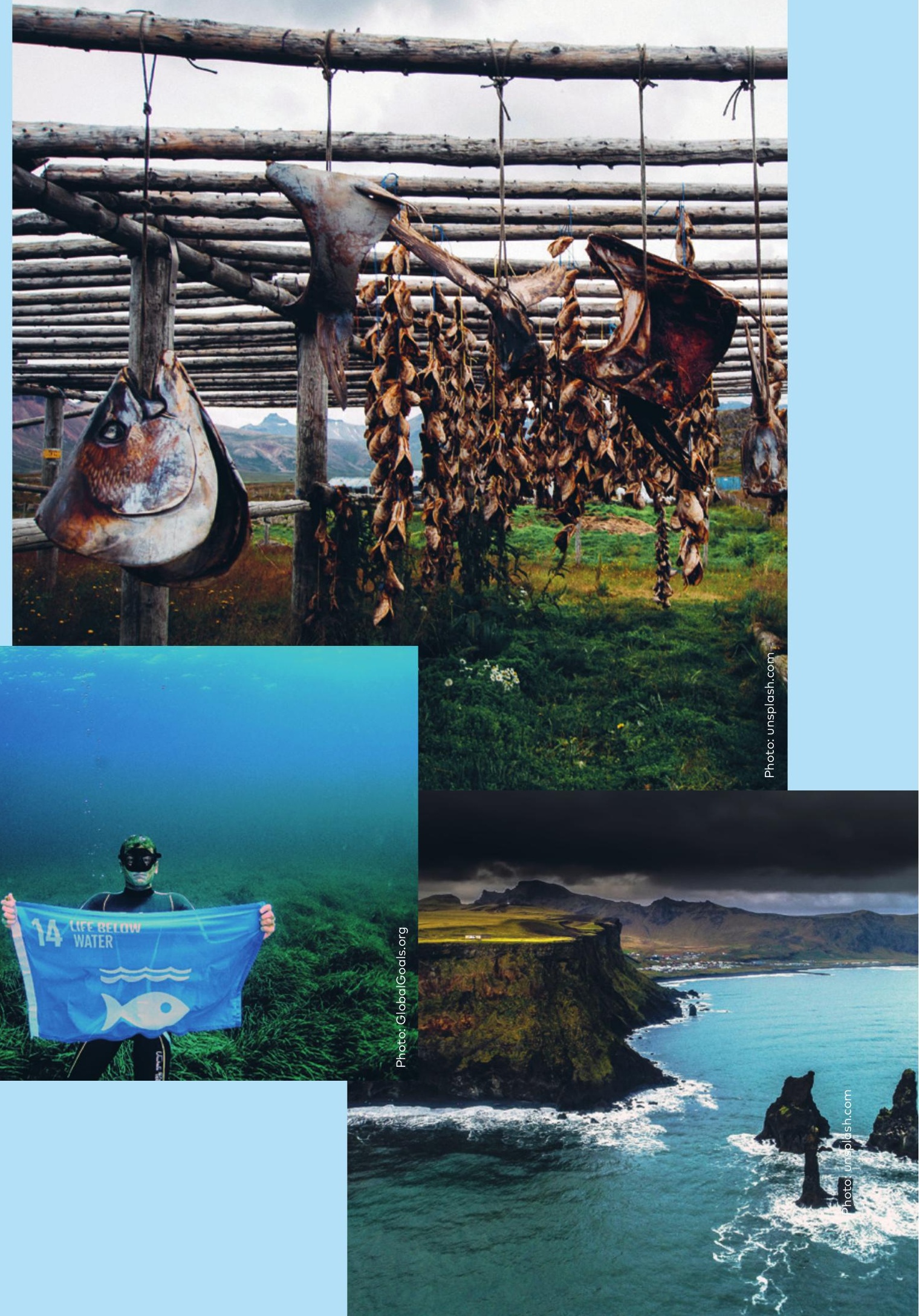




\section{THE OCEAN - BLUE GROWTH IN THE NORTH}

The ocean has linked the Nordic countries through the ages. The ocean is a highway for people and ideas, a transport network for goods and services, and a sustainable source of well-being and value. In the culture, trade and nature of all the Nordic countries the importance of the sea is indisputable. Some of the countries depend to a major extent on ocean resources, therefore healthy seas are the basis of their prosperity. The sustainability of the ocean, its resources and ecosystems is an integral part of our identity.

Sustainable utilisation and conservation of living marine resources has long been a common goal of the Nordic countries in the international arena. Iceland and Norway actively participated in the development of Law of the Sea and international rules on fisheries. Sweden has led the way in realising the fourteenth Global Goal, on Life Below Water, with the diligent support of all the Nordic countries. Denmark, Sweden and Finland have been untiring in taking initiatives and supporting policies and measures aimed at reducing pollution and building viable ecosystems in the Baltic Sea. Greenland, the Faroe Islands and the Åland Islands are island communities where every single person lives close to the sea, is always conscious of it and understands its importance.
Iceland bases its emphasis in "The Ocean - Blue Growth in the North" on the leadership that the Nordic countries have taken in this area, both at home, on a regional basis and internationally. The policy formulated by individual ministerial councils and Nordic cooperation as a whole on sustainable utilisation and conservation of marine resources, including plastics and the bioeconomy, also underlies this emphasis. Finally, this follows up on the emphases placed by the previous presidencies of Denmark, Finland, Norway and Sweden on the ocean and its resources.

Most of the challenges which Nordic seas face will only be resolved through multinational co-operation. Pollution respects no borders - sustainable utilisation of resources is a collaborative task. Under this priority on the ocean three projects have been defined which Iceland considers of particular importance. The projects reflect those challenges that are highly prioritised in the Nordic countries and internationally, and are based on the principle that Nordic co-operation can add value beyond what each country has to offer individually.

The project NordMar Ports is about ports as centres of innovation and energy transition; NordMar Plastics examines solutions to the threats that plastic in the oceans poses to ecosys- 


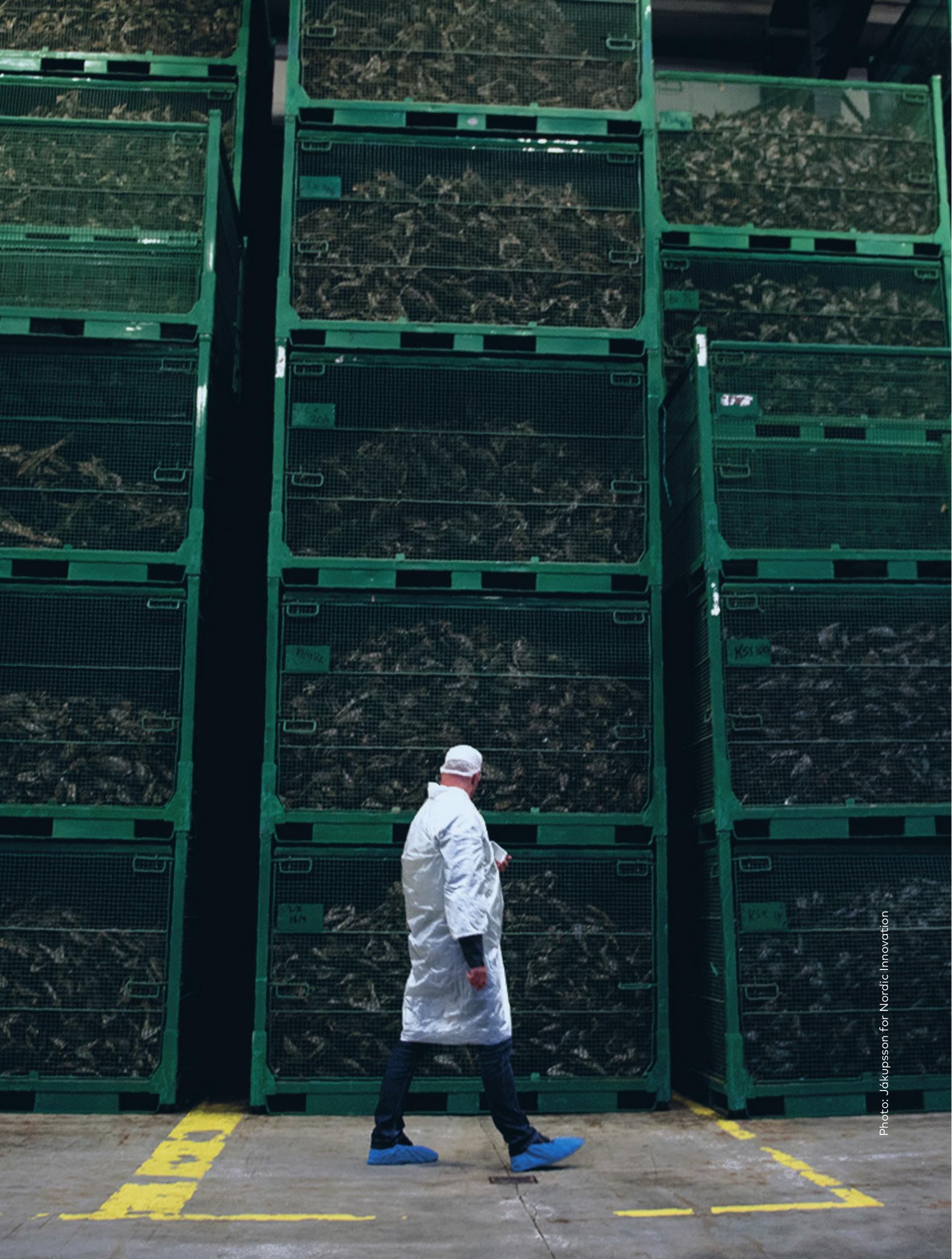


tems and our livelihoods; and NordMar Biorefine deals with the possibilities offered by full utilisation of raw materials and the production of increasingly valuable products from marine resources.

Young entrepreneurs will be involved in order to develop new solutions to selected issues focusing on the sea in collaboration with the Nordic innovation environment and Nordic Innovation.

NordMar Ports will build a co-operation network of North Atlantic ports, including those of neighbouring countries in the west: in Scotland, Canada and the United States, and in the east: in the Baltic Sea region, with the aim of defining the innovation priorities in greatest need of attention. For example, ports can play a key role in promoting energy transition in the ocean economy by providing access to sustainable energy sources. Ports will be promoted as centres of activity linking together research and education, fisheries and tourism, people and businesses. Work on each emphasis will be carried out in collaboration with stakeholders, including ports, municipalities, the innovation environment, public institutions and businesses as appropriate.

NordMar Plastics deals with plastic pollution in the oceans, which is currently one of our greatest common challenges. Among other things, efforts

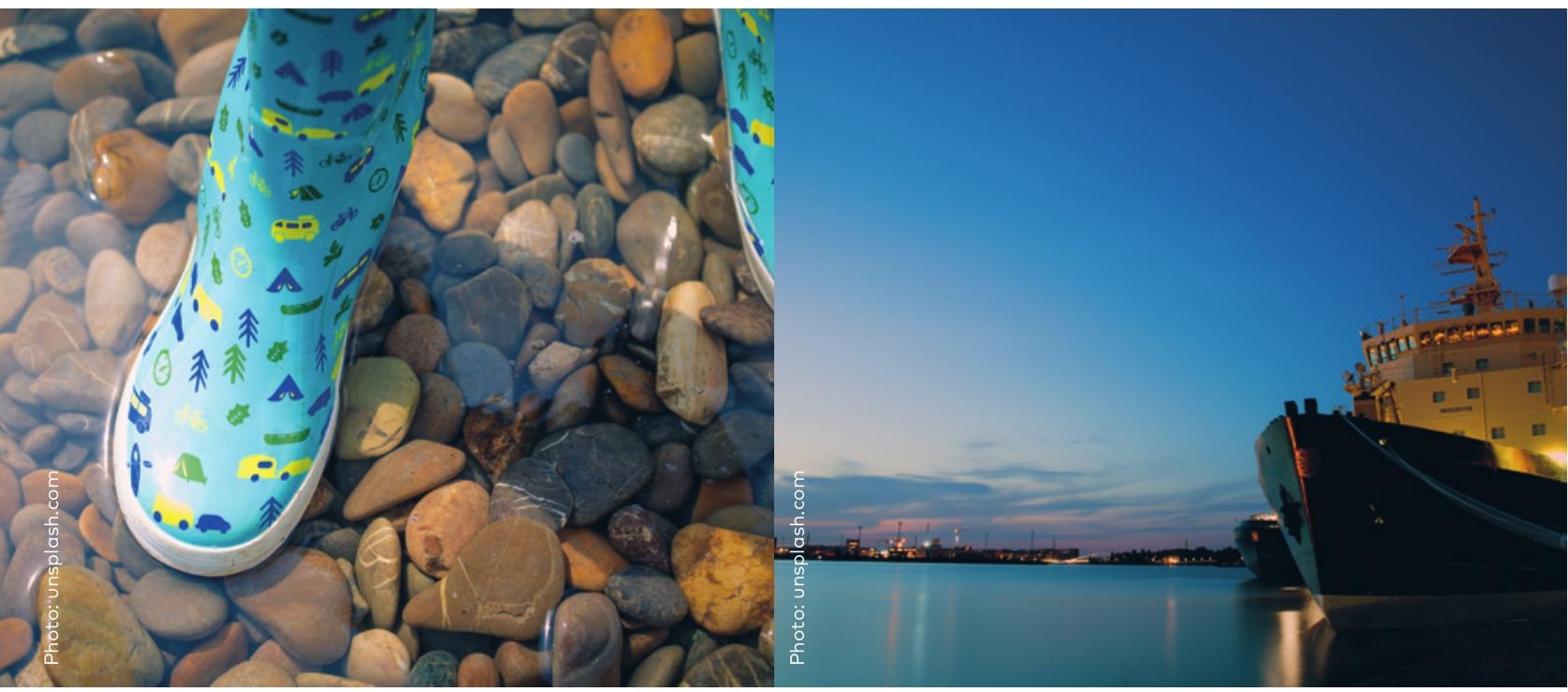




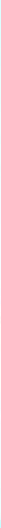

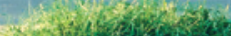

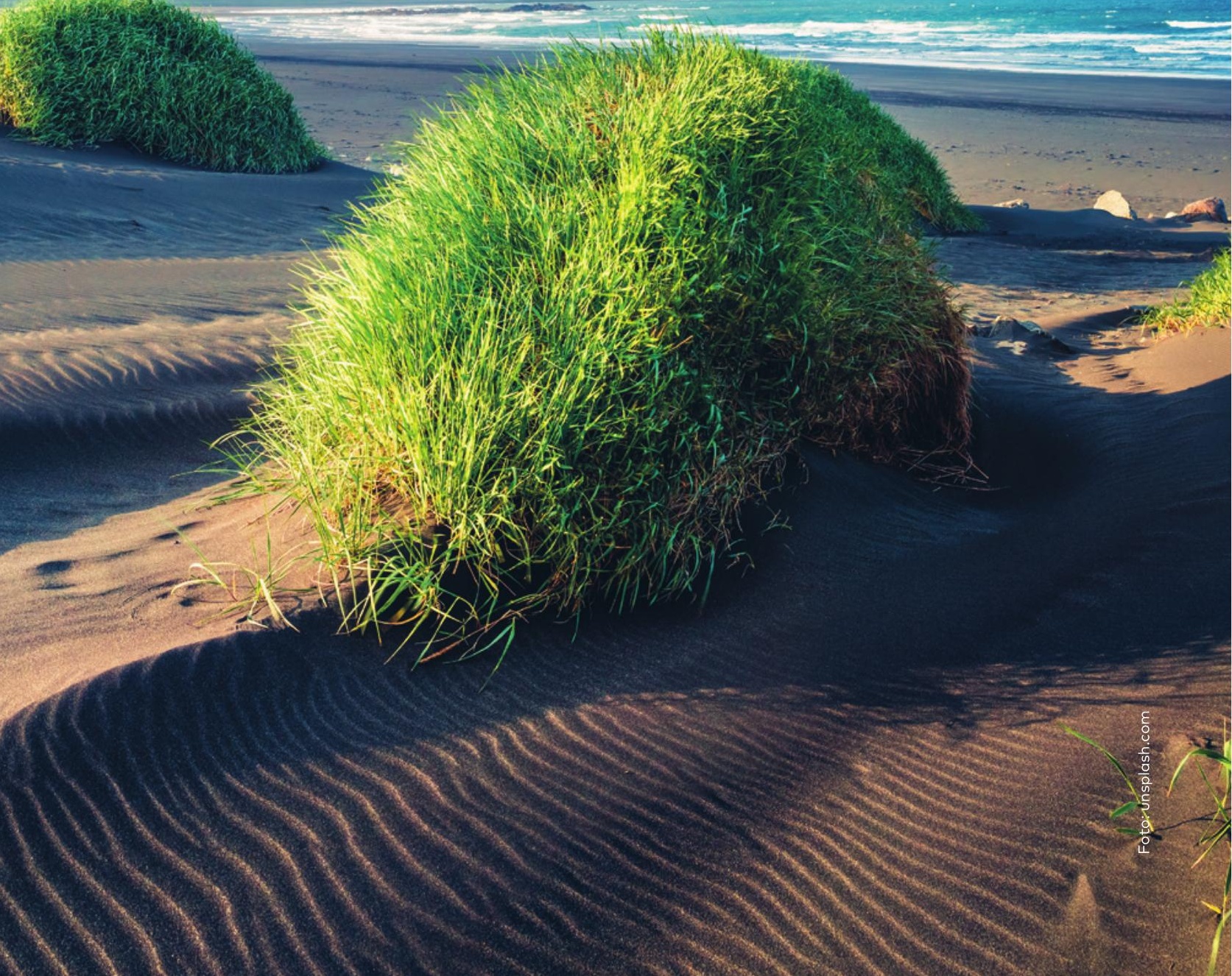


will focus on developing a joint methodology for measuring the extent of plastic in the marine environment. The public and especially young people will be informed about this challenge and events arranged to increase the growing awareness of the dangers of plastics world-wide. The project will be carried out in collaboration with Nordic research institutes, with NGOs also actively involved in the events.

NordMar Biorefine follows up on the Nordic policy focus on the bioeconomy, which aims for sustainable and better utilisation of biological resources and creating value from resources that have been under- or unused. The feasibility and potential of blue biorefineries will be evaluated specifically. The project will be carried out in collaboration with stakeholders in the Nordic countries and the Baltic Sea region. Emphasis will be placed on introducing the public, and young people especially, to the opportunities offered by the blue bioeconomy.
The ocean is not only top priority in the Nordic countries, its issues have recently earned deserved international attention. In accordance with the leadership role of Nordic countries internationally, the Presidency will present its priority concerning ocean issues at Nordic and international events during the Presidency year, including at the Our Oceans conference in Oslo in 2019. The annual joint Nordic exhibition in the Fælleshus of the Nordic embassies in Berlin in the autumn of 2019 will also be dedicated to the ocean.

The ocean is the focus of Iceland's Presidency both in the Nordic Council of Ministers and of the Arctic Council, which begins in May 2019. Thematic priorities and plans for events, analyses and assessments have been prepared in close consultation for these two Presidencies, and joint events will be held linked to ocean affairs.

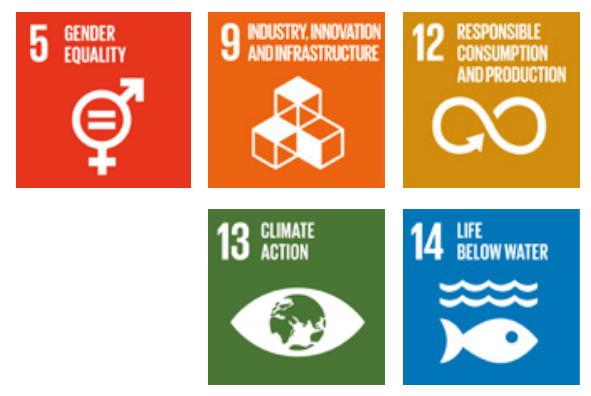





\section{A STRONG NORDIC VOICE}

These are uncertain times. Environmental affairs, development co-operation, trade and security issues, are all examples of far-reaching challenges requiring extensive international cooperation. Although there are themes aplenty, various advances have been made, such as reducing poverty and hunger in the world. The UN Global Goals and the Paris Agreement are important milestones in sustainable development and addressing climate change, and demonstrate that success can be achieved through effective international co-operation.

At the same time, the rise of extremist and isolationist forces is a cause for serious concern. The rules-based international system, built on international law and institutions, is under attack and the right of the strongest to do as they choose, by force if necessary, is gaining traction. In many parts of the world, the voices of those who show limited respect for human rights are growing increasingly loud and they disregard basic democratic principles and the rule of law. This brings racism and violence ever closer. Lessons of the past are a dire warning.

Under such international circumstances, it is important to visibly safeguard and promote fundamental values. The Nordic countries have always been at the forefront in speaking out for human rights and multilateral international co-operation. Despite being neither large nor populous, the Nordic countries have made a difference and, for instance, paved the way for progress in international environmental, peace and disarmament issues.

The Nordic model can also serve as an important example: societies where strong welfare systems and equality do not preclude, but rather underpin, strong economies. The Nordic countries have also shown that promoting gender equality is not only the right thing to do, it is also smart economic policy. The Nordic Council of Ministers has exported Nordic solutions to global challenges, for instance in environmental and energy issues. These are areas where our voices and actions matter, and where Nordic countries have a global role to play.

The Nordic countries should continue to be advocates of peace and disarmament in international fora. Peaceful resolution of disputes through international co-operation and based on international law is the goal, and here we can make a positive contribution. The Nordic countries have both formal and informal co-operation at the international level, including through embassies and foreign services. This collaboration is mutually beneficial for the Nordic countries. 
$x^{2} \cdot 2 x=1$

- $\quad 5 x^{2}+$ 
Iceland's Presidency of the Nordic

Council of Ministers emphasises that the Nordic countries should continue to take an active part in international environmental co-operation, including the UN Climate Change Conference COP25 and in supporting the Global Goals, for instance, at UN High Level Political Forums HLPF on the Global Goals and the UN General Assembly UNGA. Efforts will be made to have young people participate in presenting the Presidency's priorities and their links with the Global Goals.

Iceland's Presidency will contribute to the promotion of gender equality at the global level through our active involvement in the 63rd meeting of the UN Commission on the Status of Women (CSW), in New York, and similar events in other fora. A large international conference on the \#metoo movement and how sexual violence and harassment can be eliminated will be held in Reykjavík in September 2019, with participation from Nordic Ministers responsible for gender equality. A Nordic conference on economic empowerment and labour market equality, together with a barbershop conference on men and gender equality, will be held in the Faroe Islands around mid-year.
It is important that young people take an active part in implementing the Global Goals. For this reason, Iceland looks forward to hosting a dialogue for young people and the expert group of Generation 2030 in Reykjavik in the spring of 2019.

Due to the specific environment of the West Nordic region, emphasis will be placed on co-operation with Greenland and the Faroe Islands in implementing the Presidency programme. The Nordic Council of Ministers' policy for the North Atlantic Region (NAUST), i.e. the region extending over Greenland, Iceland, the Faroes and coastal Norway, is expected to be adopted in the beginning of next year and will be launched by the Presidency.

Nordic Day, 23 March, will be celebrated by increasing the visibility of Nordic co-operation in the public sphere and supporting the Nordic Council of Ministers' information campaign highlighting its advantages. 
In April 2019 a major international conference on the future of work will be held in Iceland. The conference is the final chapter of a Nordic project with the same name under the auspices of the Nordic Council of Ministers, focusing on challenges arising from the fourth industrial revolution and equal rights in the labour market. This conference is also linked to the 100th anniversary of the ILO.

In March 2019 there will be a joint Nordic conference on mental health and in May a conference will be held on the connection between poverty, socioeco- nomic status and public health. Both conferences will be in Reykjavik and organised by the Ministry of Welfare in Iceland in co-operation with other Nordic countries and stakeholders.

Iceland's Presidency will promote strategic proposals which have been prepared to support the future of Nordic co-operation in welfare, environmental affairs, innovation and increased mobility within the Nordic countries. To meet these ambitious goals, we have a full slate of meetings and events in Iceland and elsewhere in the Nordic countries in 2019.

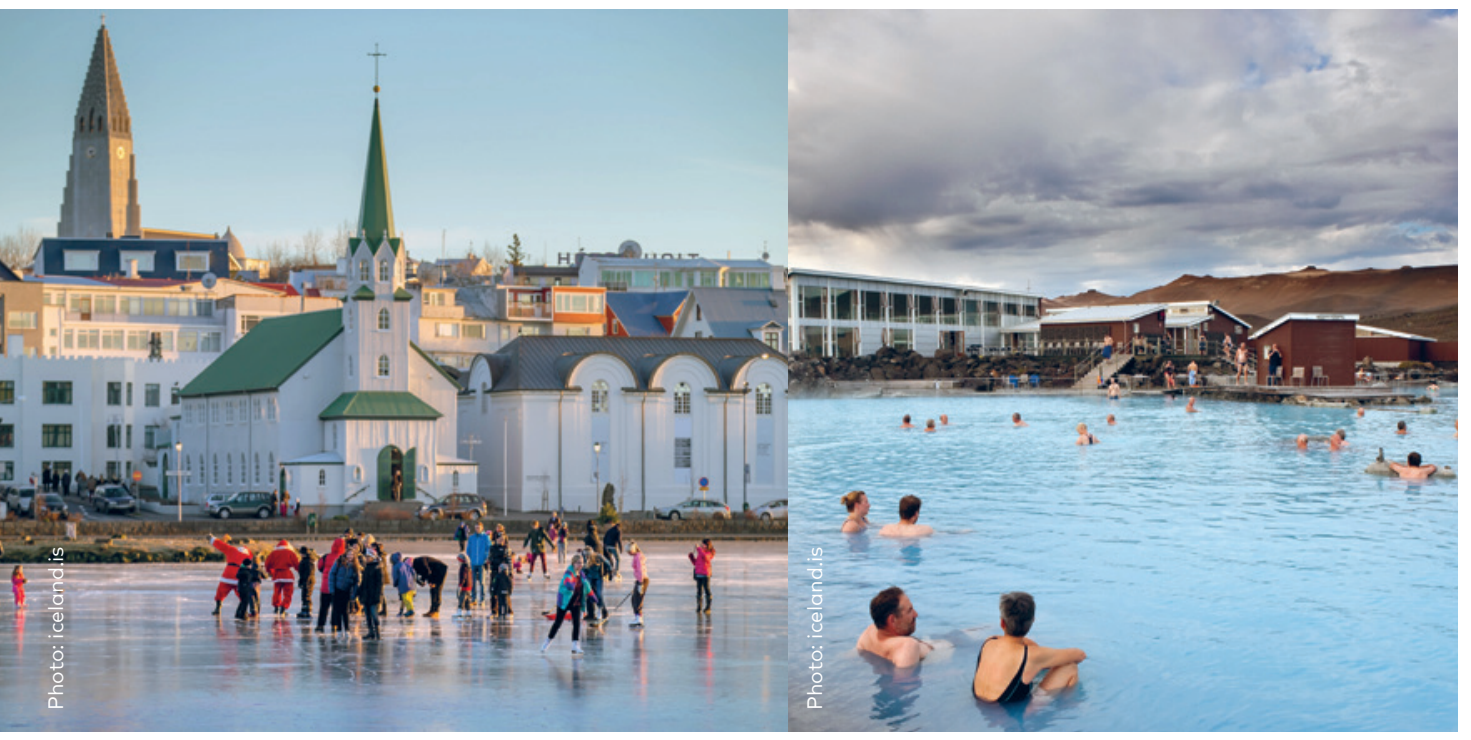


YOUTH IN THE NORDIC COUNTRIES

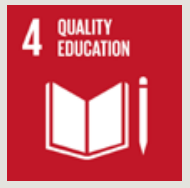

Target 4.7

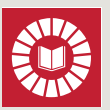

4.7 By 2030, ensure that all learners acquire the knowledge and skills needed to promote sustainable development, including, among others, through education for sustainable development and sustainable lifestyles, human rights, gender equality, promotion of a culture of peace and non-violence, global citizenship and appreciation of cultural diversity and of culture's contribution to sustainable development.

\section{SUSTAINABLE} TOURISM IN THE NORTH

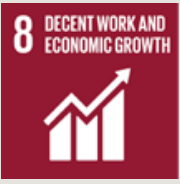

\section{Target $\mathbf{8 . 9}$

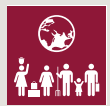

8.9 By 2030, devise and implement policies to promote sustainable tourism that creates jobs and promotes local culture and products.
THE OCEAN - BLUE GROWTH IN THE NORTH

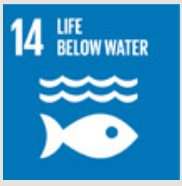

Target 14.1

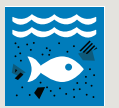

14.1 By 2025, prevent and significantly reduce marine pollution of all kinds, in particular from land-based activities, including marine debris and nutrient pollution.

\section{GENERATION 2030}

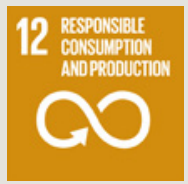

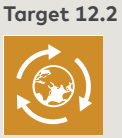

12.2 By 2030 ,

achieve the sustainable management and efficient use of natural resources.
Target 12.5

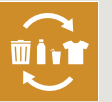

12.5 By 2030, substantially reduce waste generation through prevention, reduction, recycling and reuse.

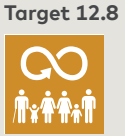

12.8 By 2030 , ensure that people everywhere have the relevant information and awareness for sustainable development and lifestyles in harmony with nature.
Target 12.B

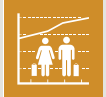

12.B Develop and implement tools to monitor sustainable development impacts for sustainable tourism that creates jobs and promotes local culture and products. 


\section{Nordic Council of Ministers \\ Nordens Hus \\ Ved Stranden 18 \\ DK-1061 Copenhagen \\ www.norden.org}

\section{ICELAND'S PRESIDENCY 2019}

Young people, sustainable tourism and ocean affairs are in focus under Iceland's Presidency of the Nordic Council of Ministers in 2019. Nordic emphases on gender equality, digitalisation and sustainable development are incorporated into the Presidency projects, together with the UN Global Goals.

The theme of the Presidency refers to the Nordic countries' friendship, as it is manifest in mobility and strong mutual co-operation. They also share common paths to the rest of the world, where the Nordic countries present themselves jointly and make their contribution to international co-operation for peace, security and environmental protection. The common paths of the future lie through the digital world.

There is deep-rooted respect for the principles of democracy and rule of law in the Nordic countries. We are determined to continue to be peaceful and diverse welfare societies, where culture and education flourish, and everyone is entitled to enjoy life's opportunities. Societies where innovation goes hand-in-hand with the interests of nature, employment and a vital economy.

Nordic co-operation has shown that it is better to build bridges than walls. There is nothing old-fashioned about co-operation, friendship and respect. These basic Nordic values are always at the forefront.

ANP 2018:828

ISBN 978-92-893-5865-1 (PRINT)

ISBN 978-92-893-5866-8 (PDF)

ISBN 978-92-893-5867-5 (EPUB) 